\title{
High Temperature Oxidation Behavior of AISI 304 and AISI 430 Stainless Steels
}

\author{
Carlos Eduardo Reis de Carvalho ${ }^{\mathrm{a}}$, Geraldo Magela da Costa ${ }^{\mathrm{a} *}$, André Barros Cota $^{\mathrm{b}}$,Edson Hugo Rossi \\ ${ }^{a}$ Departamento de Química, Universidade Federal de Ouro Preto, \\ Campus Universitário - Morro do Cruzeiro, 35400 Ouro Preto - MG, Brazil \\ ${ }^{\mathrm{b}}$ Departamento de Física, Redemat, Universidade Federal de Ouro Preto, \\ 35400 Ouro Preto - MG, Brazil \\ 'ACESITA S.A., 35180-018 Timóteo - MG, Brazil
}

Received: April 26, 2006; Revised: November 27, 2006

\begin{abstract}
The oxidation behavior of AISI 304 and AISI 430 stainless steels was investigated from $1100{ }^{\circ} \mathrm{C}$ up to $1200{ }^{\circ} \mathrm{C}$. Mössbauer spectroscopy and $\mathrm{x}$ ray diffraction were used to access the phase composition of the formed scales. The main crystalline phases found in the oxidized materials at temperatures above $1100{ }^{\circ} \mathrm{C}$ were hematite and magnetite for AISI 430 steel, and hematite and a spinel-like phase for AISI 304 steel. Hematite was found to be the dominant oxide at lower temperatures, whereas magnetite preferentially forms at higher temperatures. The activation energy for oxidation is smaller for AISI 430 steel in relation to AISI 304 steel in the range of studied temperatures, and therefore the AISI 430 steel is less resistant towards oxidation at high temperatures.
\end{abstract}

Keywords: AISI 304 and AISI 430 stainless steel, oxidation, Mössbauer spectroscopy

\section{Introduction}

Austenitic stainless steels are very corrosion resistant in a wide range of corrosive media and they can be used in a wide range of temperatures, from cryogenic conditions up to about $1150{ }^{\circ} \mathrm{C}$. The AISI 304 austenitic steels are widely used in chemical, petrochemical and pharmaceutical industries. Recently, ferritic stainless steels have been developed to substitute austenitic stainless steels in some applications, as automotive exhaust components, specially the upstream part of the exhaust line (manifold, down-pipe, converter shell), where temperatures can reach $1100^{\circ} \mathrm{C}$. They have advantage of lower costs than austenitic grades due to the absence of nickel, and also present lower expansion coefficient than austenitic steels, which is a great advantage when temperature cycling resistance is needed ${ }^{1,2}$.

A number of studies have been made on the initial oxidation of $\mathrm{Fe}-\mathrm{Cr}$ alloys and the effect of oxygen partial pressure and of different atmospheres on the properties of the oxides, since the high-temperature oxidation resistance of these alloys depends on the oxide properties $^{2,7}$.

Knowledge of the initial oxidation behavior, hardness and adherence of the oxide formed on $\mathrm{Fe}-\mathrm{Cr}$ alloys and stainless steels at higher temperatures at atmospheric pressure is important in processes such as annealing, acid pickling and cold working.

In this work, the high temperature oxidation behavior of an austenitic stainless steel AISI 304 type is compared to the behavior of a ferritic stainless steel AISI 430. The scales formed in a tubular furnace under dynamic synthetic air atmosphere with $3 \mathrm{ppm}$ of humidity were analyzed by x ray diffraction and Mössbauer spectroscopy.

\section{Experimental}

Samples of AISI 304 and AISI 430 steels with dimensions of approximately $1.0 \times 2.0 \times 0.3 \mathrm{~cm}$ (width, length and thickness, respectively) were carefully polished to remove the original scale which was formed during the rolling process. The chemical compositions of these steels are listed in Table 1.
The isothermal oxidation experiments were done in a tubular furnace under dynamic synthetic air atmosphere with $3 \mathrm{ppm}$ of humidity, during 10,20 and 30 minutes at the temperatures of 1100 , $1125,1150,1175$ and $1200{ }^{\circ} \mathrm{C}$. Samples were weighted before and after each experiment using an analytical balance with a sensitivity of $0.1 \mathrm{mg}$, and the results are given in terms of mass $(\mathrm{mg})$ by surface area $\left(\mathrm{cm}^{2}\right)$.

$\mathrm{X}$ ray diffraction (XRD) patterns were obtained with a XRD6000 Shimadzu diffractrometer equipped with a cobalt tube and iron filter. The scans were carried out from $20^{\circ}$ to $65^{\circ}$ ( 2 theta) at a speed of $2^{\circ} \mathrm{min}^{-1}$. Powders were used when the formed oxidized layer was not firmly adhered to the surface of the metal. In these cases they were gently removed with the help of a spatula. Cell parameters were calculated by least-square refinement after subtracting the background and the $\mathrm{K} \alpha 2$ contribution and using intensity and angular weighting of the most intense peaks.

Mössbauer spectra (MS) were collected at room-temperature with a spectrometer using a constant-acceleration drive with triangular reference signal, 512 channels and in the velocity range of - 11 to $+11 \mathrm{~mm} / \mathrm{s}$ (increment of $\sim 0.045 \mathrm{~mm} / \mathrm{s}$ ). Velocity calibration was achieved from the MS of a standard $\alpha$-Fe foil at RT, and the isomer shifts are quoted relative to $\alpha-\mathrm{Fe}$. The absorbers were prepared mixing approximately $20 \mathrm{mg}$ of the powders with sucrose in order to obtain a thickness of about $10 \mathrm{mg} \mathrm{Fe} / \mathrm{cm}^{2}$.

\section{Results and Discussion}

\subsection{Kinetics}

The gain of mass by surface area $(\Delta \mathrm{M} / \mathrm{S})$ as a function of time is shown in Figure 1 for AISI 304 and 430 steels, for the different temperatures used. As the temperature and/or time are increased, there is a large increase in the oxidation of both steels, the more so for the AISI 430 steel. In spite of the small number of data points, 
Table 1. Chemical compositions (in wt. (\%)) of the AISI 304 and AISI 430 stainless steels.

\begin{tabular}{ccccccccc}
\hline Steel & $\mathrm{C}$ & $\mathrm{Mn}$ & $\mathrm{Si}$ & $\mathrm{Cr}$ & $\mathrm{Ni}$ & $\mathrm{P}$ & $\mathrm{S}$ & $\mathrm{N}$ \\
\hline AISI 304 & 0.041 & 1.17 & 0.45 & 18.14 & 8.04 & 0.031 & 0.0018 & 0.048 \\
AISI 430 & 0.047 & 0.37 & 0.32 & 16.14 & 0.21 & 0.027 & 0.0011 & 0.049 \\
\hline
\end{tabular}

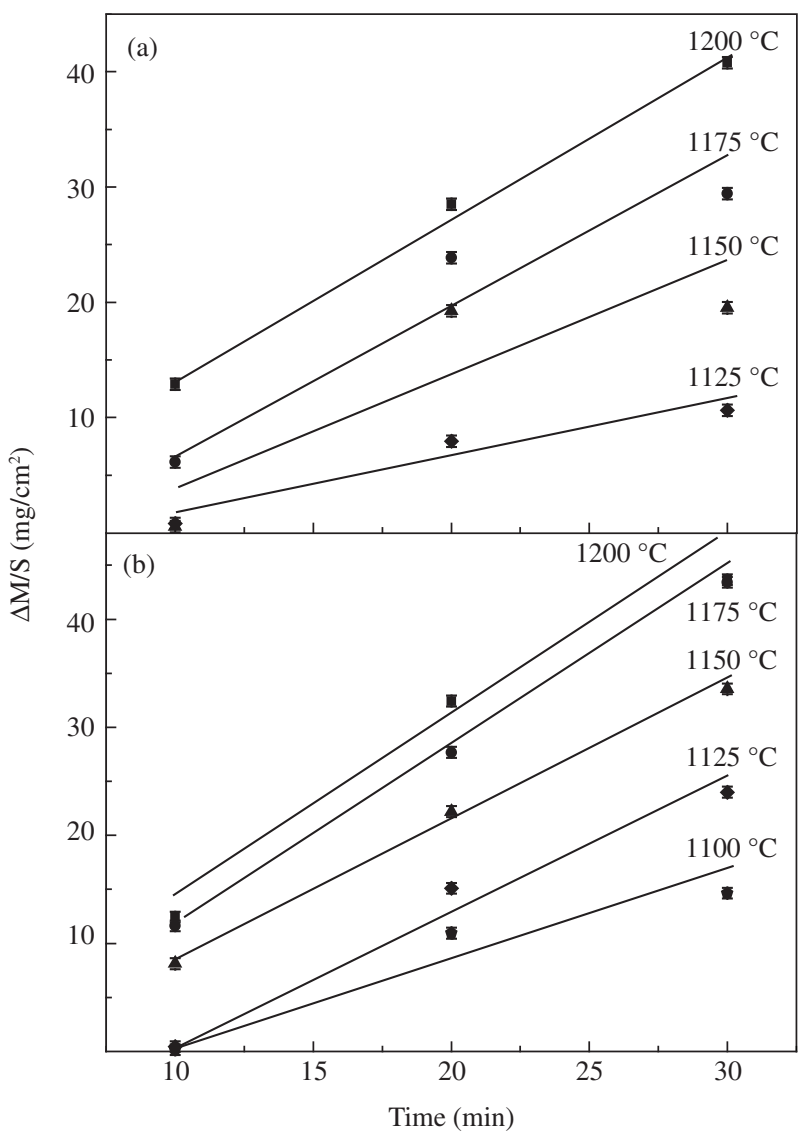

Figure 1. Mass variation by surface area as a function of time for a) AISI 304; and b) AISI 430 steels. The solid lines are the best linear fits to the experimental data.

and of the large scatter at some temperatures, it seems that there is a linear relationship between $(\Delta \mathrm{M} / \mathrm{S})$ and the time $(\mathrm{t})$, indicating that the kinetics might follow a linear law, according to the equation $(\Delta \mathrm{M} / \mathrm{S})=\mathrm{k}_{\mathrm{L}} . \mathrm{t}$, where $\mathrm{k}_{\mathrm{L}}$ is linear oxidation constant. These constants were obtained by least-square fitting of the experimental data shown in Figure 1.

The Arrhenius plots are shown in Figure 2, and from these data it was possible to calculate the activation energies for each steel. As mentioned above, the AISI $430(\mathrm{Q}=123 \mathrm{~kJ} / \mathrm{mol})$ showed to be less resistant against oxidation, and indeed the activation energy for this steel is about half of the value found for the AISI $304(\mathrm{Q}=226 \mathrm{~kJ} / \mathrm{mol})$.

\subsection{Characterization of the oxide scale}

The XRD patterns of non-oxidized and oxidized steels are shown in Figures 3 and 4 (AISI 304 and AISI 430 respectively). For the sake of comparison, the diffractograms of the original scales formed during the rolling process are also shown. Hematite and magnetite are the only phases detected in this scale. The presence of the peak relative to the metallic phase in the AISI 430 steel is certainly related to the small thickness of the original scale.

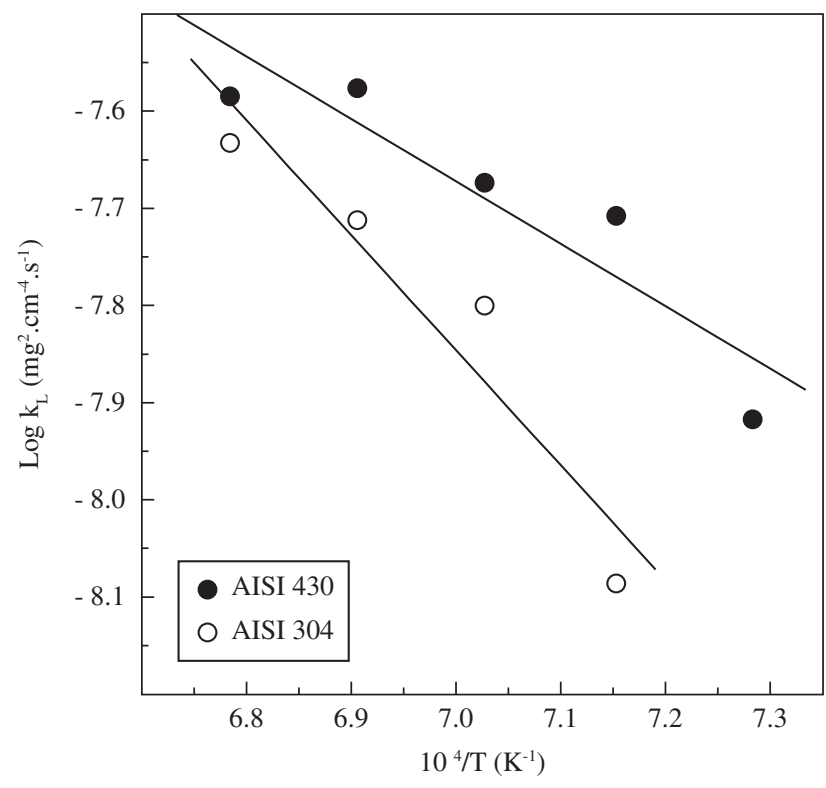

Figure 2. Arrhenius plots of the linear oxidation constants for AISI 304 and AISI 430 steels.

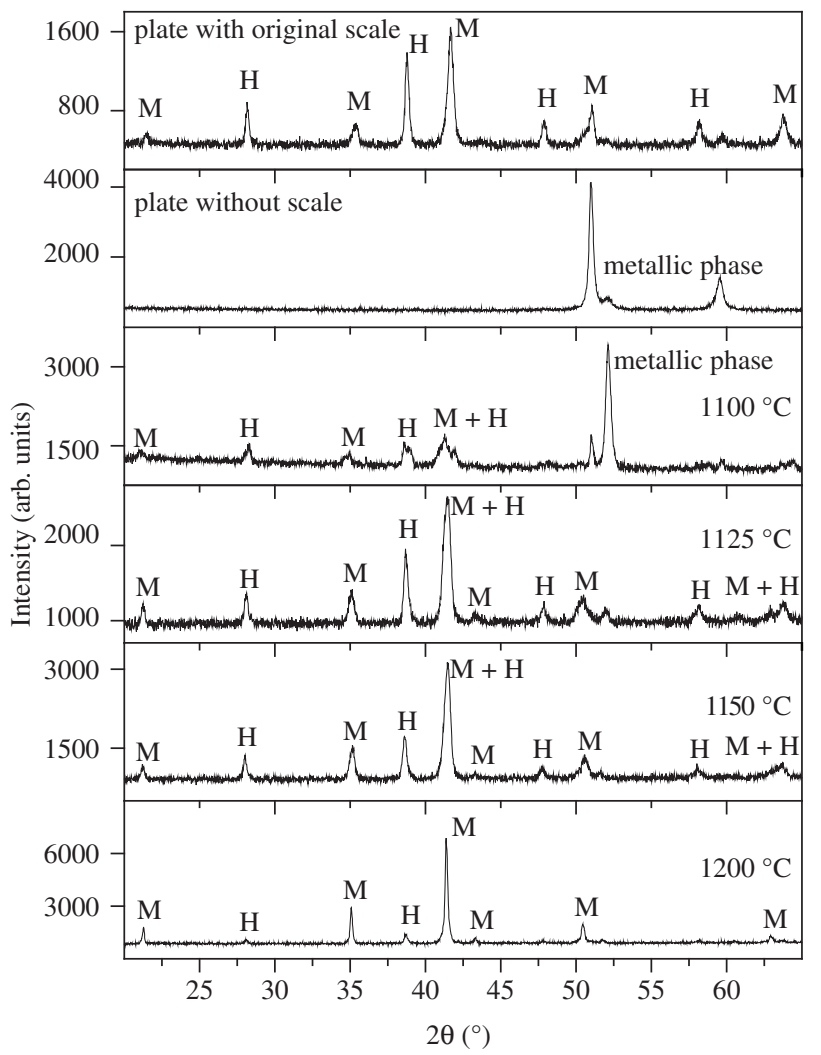

Figure 3. $\mathrm{X}$ ray diffraction patterns of the original plates and of the oxidized samples during 30 minutes of AISI 304 steel. $\mathrm{H}=$ hematite and $\mathrm{M}=$ magnetite.

Heating up to $1100^{\circ} \mathrm{C}$ both steels show the presence of additional peaks that were associated to the presence of a mixture of hematite $\left(\alpha-\mathrm{Fe}_{2} \mathrm{O}_{3}\right)$ and eskolaite $\left(\mathrm{Cr}_{2} \mathrm{O}_{3}\right)$. No nickel-bearing phases could be identified at any temperature for the AISI 304 steel, as already suggested in literature ${ }^{5}$. At higher temperatures the major phases seem 
to be hematite and magnetite, and no chromium-bearing phases were identified. It can also be noticed from Figures 3 and 4 that the intensities of the hematite peaks decreases whereas those of magnetite increases with increasing the temperature of thermal treatment. In addition, the line widths of all peaks narrow as the temperature increases, indicating either an increase of the particle sizes and/or an enhancement of the crystallinity of both phases. The appearance of the scale formed after heating at $1200{ }^{\circ} \mathrm{C}$ is similar to the original scale formed during the rolling process.

One intriguing aspect in the XRD patterns of the AISI 430 steel heated at $1100{ }^{\circ} \mathrm{C}$ and $1125^{\circ} \mathrm{C}$ is the presence of a sharp and intense peak near $46^{\circ}$ ( 2 theta). This peak could not be associated to any new phase, and therefore might be due to a texture effect. To verify that this was the case, the scale was removed and a diffractogram of the powder was obtained. The XRD pattern showed the presence of hematite and magnetite, and the above mentioned peak almost disappeared. The intensity of the peak corresponding to the (006) plane of hematite, which occurs at $\sim 46^{\circ}$, is only $1 \%$ in a non-oriented sample. Thus, we can conclude that the hematite formed at $1100{ }^{\circ} \mathrm{C}$ and $1125^{\circ} \mathrm{C}$ shows a pronounced effect of preferred orientation.

The distinction by XRD between hematite $(a=5.036 \AA)$, eskolaite $(a=4.959 \AA)$ and the intermediate compound (Cr.Fe $)_{2} \mathrm{O}_{3}(a=5.015 \AA)$ is not easy because of the similarities of the cell parameters. This means that the differences of the peak-positions are rather small, making it difficult to distinguish these phases. The same is true for magnetite $(a=8.396 \AA)$ and cromite $(a=8.379 \AA)$. The major difficulty arises from the fact that no internal standard could be added to the samples to correct an eventual instrumental shift. In spite of this limitation, the cell parameters were calculated as an attempt of obtaining some indication of the predominant phase. The calcula-

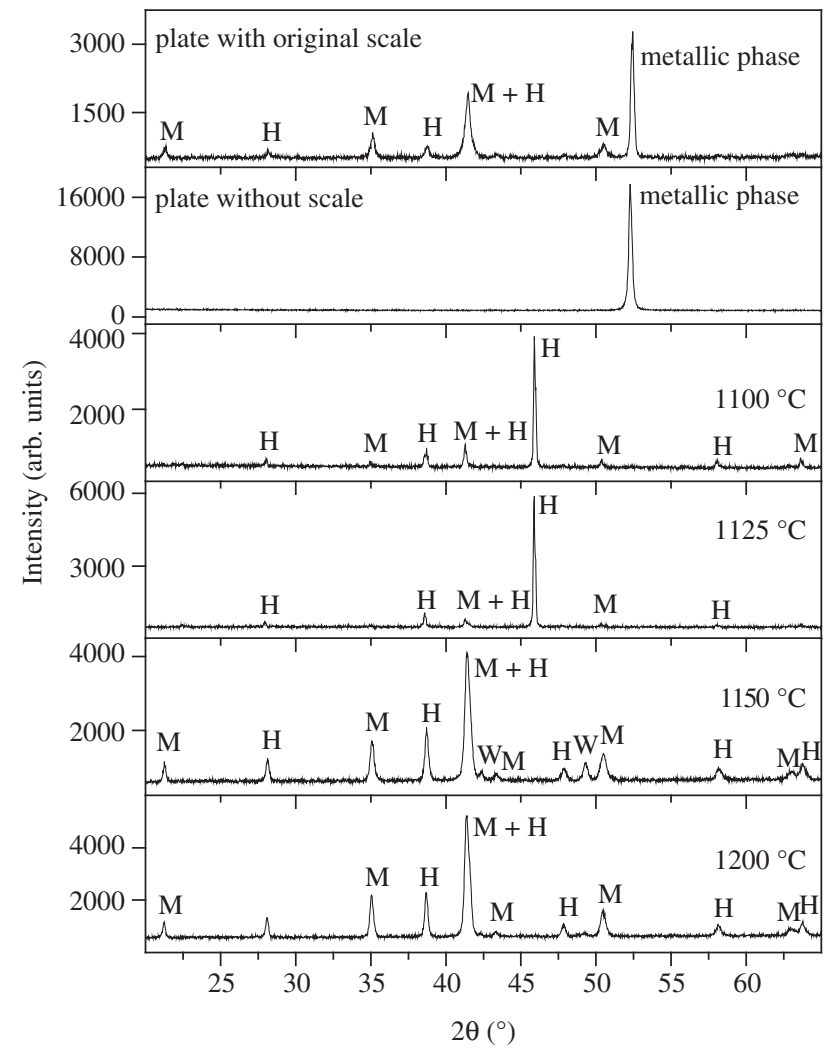

Figure 4. $\mathrm{X}$ ray diffraction patterns of the original plates and of the oxidized samples during 30 minutes of AISI 430 steel. $\mathrm{H}=$ hematite, $\mathrm{M}=$ magnetite and $\mathrm{W}=$ wustite. tions were done after subtraction of the background and of the K $\alpha 2$ contribution and using the most intense peaks of each phase. An error estimation was made considering an instrumental shift of $0.2^{\circ}$ ( 2 theta), which results in an average error of about $0.03 \AA$ in the cell parameters. These parameters are shown in Figures 5 and 6 for the samples heated between $1100-1200{ }^{\circ} \mathrm{C}$ and for the times of 10,20 and 30 minutes. Most of the data are more or less scattered around $8.40 \AA$ and $5.04 \AA$, suggesting that indeed magnetite and hematite are the dominant phases. However, for $1100{ }^{\circ} \mathrm{C}$ the calculated cell parameters are closer to that of eskolaite, thus confirming the presence of this oxide in the scale of both steels.

One technique that can give valuable information about all iron-bearing phases and that in principle can distinguish the above mentioned oxides is Mössbauer spectroscopy ${ }^{8}$. Mössbauer spectra at room temperature of some selected samples of AISI 304 and 430 steels are shown in Figure 7 and the obtained numerical results of the fits are listed in Tables 2 and 3.

The hyperfine magnetic fields $(517 \mathrm{kOe})$, as well as the linewidth $(\sim 0.26 \mathrm{~mm} / \mathrm{s})$ of the hematite present in both the steels are characteristic of a stoichiometric phase and therefore the compound $(\mathrm{Cr} . \mathrm{Fe})_{2} \mathrm{O}_{3}$ is unlikely to exist in these samples ${ }^{6}$.

The other magnetic phase identified in all Mössbauer spectra possesses the parameters of magnetite, and no variation in the values of the magnetic fields was observed. However, samples of AISI 304 steel present the two sextets of magnetite with relative area-ratios of about $1: 1$, in contrast with the samples of AISI 430 steel for which this ratio is close to 1:1.88. For stoichiometric magnetite $\left(\left[\mathrm{Fe}^{3+}\right]\left(\mathrm{Fe}^{3+} \mathrm{Fe}^{2+}\right) \mathrm{O}_{4}\right)$ the ratio of iron ions in the tetrahedral and octahedral sites is $1: 2$, whereas the area ratios are close to 1:1.88 due to differences in the recoilless fractions ${ }^{9}$. Therefore, it can be concluded that the scale of the AISI 430 steel formed between $1100{ }^{\circ} \mathrm{C}$ and $1200{ }^{\circ} \mathrm{C}$ present in its composition stoichiometric magnetite. In contrast, the behavior

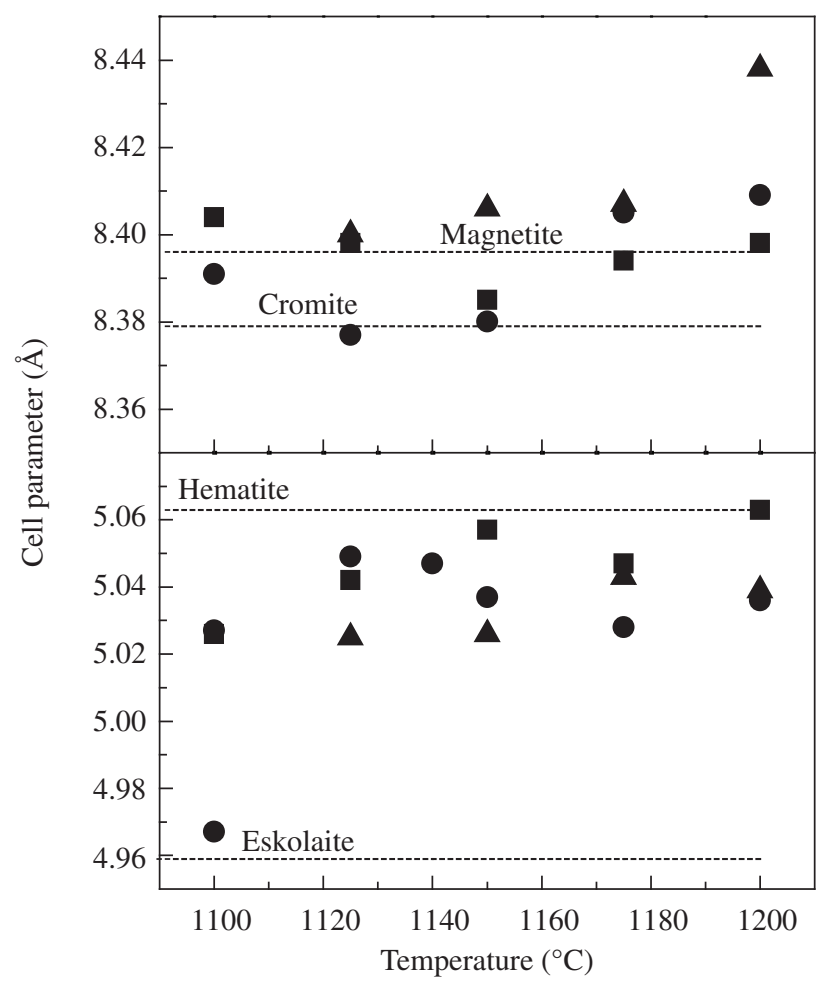

Figure 5. Cell parameters as a function of the temperature of thermal treatment for the phases found in AISI 304 steel: a 30 minutes; 20 minutes; $\Delta 10$ minutes. 


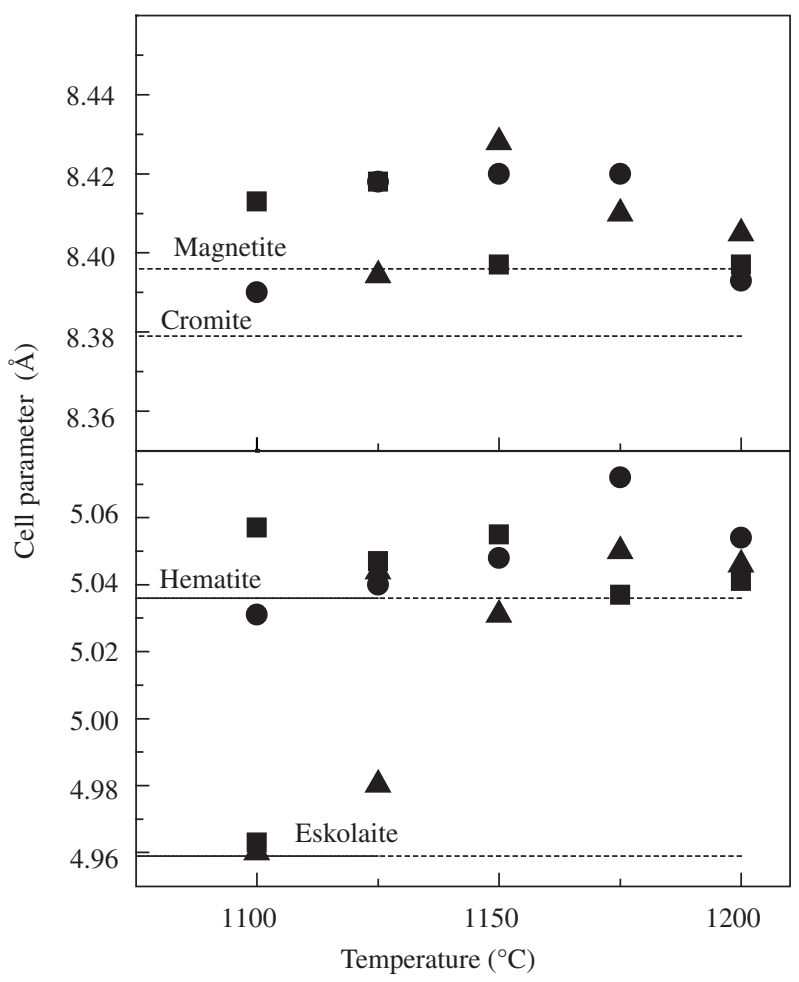

Figure 6. Cell parameters as a function of the temperature of thermal treatment for the phases found in AISI 430 steel: -30 minutes; -20 minutes; $\Delta 10$ minutes.

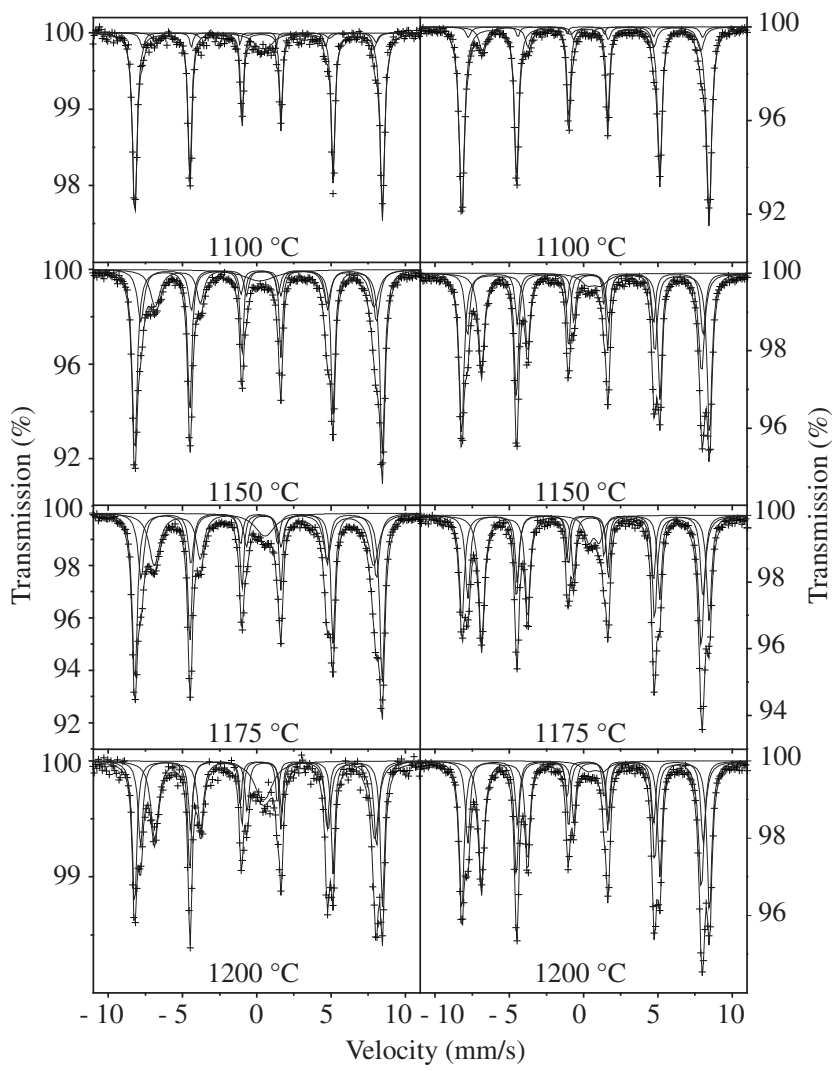

Figure 7. Mössbauer spectra at room temperature of AISI 304 steel (left) and AISI 430 steel (right) treated at the indicated temperatures. Crosses represent the experimental data and the solid lines represent the adjusted sub spectra and their sum. of the AISI 304 steel is different and its scale formed at those above mentioned temperatures contain either a non-stoichiometric magnetite or a nickel and/or chromium spinel phase. In what follows, these phases will be generically treated as magnetite.

Another important result from the Mössbauer spectra is related to the relative area-ratios of hematite and magnetite (Figure 8 ). The relative area of hematite decreases from about $84 \%$ at $\sim 1100{ }^{\circ} \mathrm{C}$ to $30 \%$ at $1200{ }^{\circ} \mathrm{C}$ whereas the contribution of magnetite increases, being both trends approximately linear. This correlation between the decrease of the amount of hematite and the increase of magnetite, and the absence of any new iron-bearing phase, indicates that magnetite is preferentially formed at higher temperatures while the formation of hematite preferentially occurs at lower temperatures.

The spectra shown in Figure 7 also contain a weak doublet, whose contribution is more or less constant $(\sim 5 \%)$ for all investigated samples. The derived hyperfine parameters for this doublet suggest that it is due to the presence of wustite.

\section{Conclusions}

The oxidation behavior at high temperatures of AISI 304 and AISI 430 stainless steels is strongly affected by the temperature and time, especially above $1100{ }^{\circ} \mathrm{C}$. The activation energy for oxidation is smaller for AISI 430 steel in relation to AISI 304 steel in the range of studied temperatures, and therefore the AISI 430 steel is less resistant towards oxidation at high temperatures in synthetic air atmosphere. The adherence of the formed scale is directly related

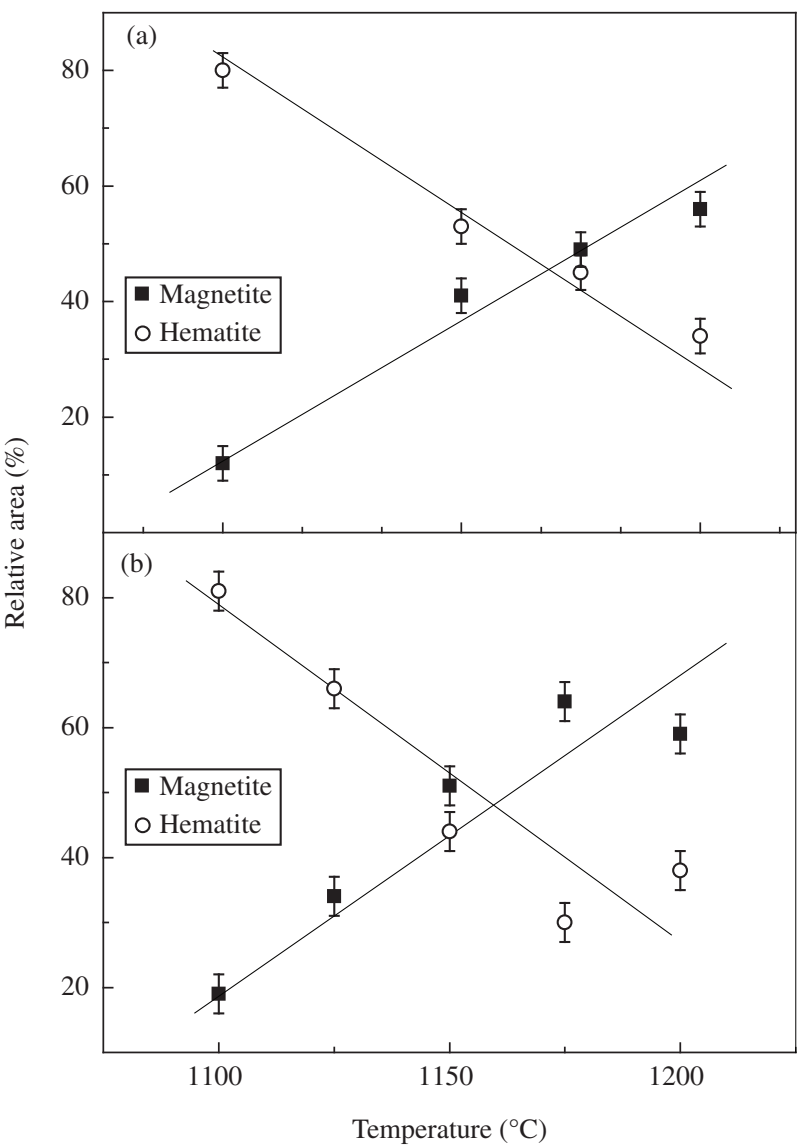

Figure 8. Variation of hematite and magnetite contents as a function of the heating temperature for a) AISI 304 and b) AISI 430 steels. 
Table 2. Hyperfine parameters obtained from the Mössbauer spectra at room temperature of AISI 304 steel heated at the indicated temperatures. $\mathrm{H}_{\mathrm{hf}}=$ hyperfine magnetic field (kOe); $\delta=$ isomer shift relative to $\alpha$-Fe. $(\mathrm{mm} / \mathrm{s}) ; 2 \varepsilon_{\mathrm{Q}}=$ quadrupole shift $(\mathrm{mm} / \mathrm{s}) ; \mathrm{S}=$ relative area $(\%)$.

\begin{tabular}{|c|c|c|c|c|c|c|c|c|c|c|c|c|}
\hline \multirow[t]{2}{*}{$\mathrm{T}\left({ }^{\circ} \mathrm{C}\right)$} & \multicolumn{4}{|c|}{ Hematite } & \multicolumn{8}{|c|}{ Magnetite } \\
\hline & $\mathrm{H}_{\mathrm{hf}}$ & $\delta$ & $2 \varepsilon_{\mathrm{Q}}$ & $\mathrm{S}$ & $\mathrm{H}_{\mathrm{hf} 1}$ & $\delta_{1}$ & $2 \varepsilon_{\mathrm{Q} 1}$ & $\mathrm{~S}_{1}$ & $\mathrm{H}_{\mathrm{hf} 2}$ & $\delta_{2}$ & $2 \varepsilon_{\mathrm{Q} 2}$ & $\mathrm{~S}_{2}$ \\
\hline 1100 & 517 & 0.33 & -0.19 & 80 & 492 & 0.22 & 0.01 & 8 & 463 & 0.65 & 0.00 & 4 \\
\hline 1150 & 517 & 0.33 & -0.19 & 53 & 492 & 0.27 & -0.05 & 20 & 457 & 0.61 & 0.06 & 21 \\
\hline 1175 & 516 & 0.33 & -0.19 & 45 & 491 & 0.25 & 0.00 & 21 & 458 & 0.60 & 0.00 & 28 \\
\hline 1200 & 518 & 0.33 & -0.19 & 34 & 492 & 0.24 & -0.02 & 23 & 459 & 0.64 & 0.02 & 33 \\
\hline
\end{tabular}

Table 3. Hyperfine parameters obtained from the Mössbauer spectra at room temperature of AISI 430 steel heated at the indicated temperatures. $\mathrm{H}_{\mathrm{hf}}=$ hyperfine magnetic field (kOe); $\delta=$ isomer shift relative to $\alpha-\mathrm{Fe} .(\mathrm{mm} / \mathrm{s}) ; 2 \varepsilon_{\mathrm{O}}=$ quadrupole shift $(\mathrm{mm} / \mathrm{s}) ; \mathrm{S}=$ relative area $(\%)$.

\begin{tabular}{|c|c|c|c|c|c|c|c|c|c|c|c|c|}
\hline \multirow[t]{2}{*}{$\mathrm{T}\left({ }^{\circ} \mathrm{C}\right)$} & \multicolumn{4}{|c|}{ Hematite } & \multicolumn{8}{|c|}{ Magnetite } \\
\hline & $\mathrm{H}_{\mathrm{hf}}$ & $\delta$ & $2 \varepsilon_{\mathrm{Q}}$ & $S$ & $\mathrm{H}_{\mathrm{hf} 1}$ & $\delta_{1}$ & $2 \varepsilon_{\mathrm{Q} 1}$ & $\mathrm{~S}_{1}$ & $\mathrm{H}_{\mathrm{hf} 2}$ & $\delta_{2}$ & $2 \varepsilon_{\mathrm{Q} 2}$ & $\mathrm{~S}_{2}$ \\
\hline 1100 & 517 & 0.33 & -0.19 & 81 & 492 & 0.27 & 0.00 & 6 & 456 & 0.63 & 0.00 & 13 \\
\hline 1125 & 517 & 0.33 & -0.19 & 66 & 493 & 0.25 & -0.01 & 13 & 457 & 0.61 & 0.02 & 21 \\
\hline 1150 & 517 & 0.33 & -0.18 & 44 & 492 & 0.23 & -0.02 & 18 & 459 & 0.63 & 0.02 & 33 \\
\hline 1175 & 517 & 0.33 & -0.18 & 30 & 492 & 0.23 & -0.01 & 23 & 459 & 0.63 & 0.02 & 41 \\
\hline 1200 & 517 & 0.33 & -0.17 & 38 & 491 & 0.24 & -0.01 & 21 & 459 & 0.63 & 0.02 & 38 \\
\hline
\end{tabular}

to its composition, and therefore the characterization of the iron oxides present in the oxidized layer is very important. The main crystalline phases found in the oxidized materials at temperatures above $1100{ }^{\circ} \mathrm{C}$ were hematite and magnetite for AISI 430 steel, and hematite and a spinel-like phase for AISI 304 steel. The presence of this spinel-like phase can be associated to the higher oxidtion resistance of the AISI 304 steel. Hematite was found to be the dominant oxide at lower temperatures, whereas magnetite preferentially forms at higher temperatures.

\section{Acknowledgments}

This work was partially funded by CNPq (Brazil).

\section{References}

1. Sedricks JA. Corrosion of Stainless Steels. Princeton: John Wiley \& Sons; 1979. p. 282

2. Sabioni ACS, Huntz AM, Luz EC, Mantel M, Haut C. Comparative study of high temperature oxidation behaviour in AISI 304 and AISI 439 stainless steels. Materials Research. 2003; 6(2):179-185.
3. Vesel A, Mozetic M, Zalar A. Oxidation of AISI 304L Stainless Steel Surface with Atomic Oxigen. Applied Surface Science. 2002; 200:94-103.

4. Greeff AP, Louw CW, Swart HC, The Oxidation of Industrial FeCrMo Steel. Corrosion Science. 2000; 42(10):1725-1740.

5. Saeki I, Konno H, Furuichi R, Nakamura T, Mabuchi BK, Itohd M. The Effect of the Oxidation Atmosphere on the Initial Oxidation of Type 430 Stainless Steel at 1273K. Corrosion Science. 1988; 40(2/3):191-200.

6. Ostwald C, Grabke HJ. Initial Oxidation and Chromium Diffusion. I. Effects of Surface Working on 9-20\% Cr Steels. Corrosion Science. 2004; 46(5):1113-1127

7. Saeki I, Konno I, Furuichi R. The initial Oxidation of Type 430 Stainless Steel in $\mathrm{O}_{2}-\mathrm{H}_{2} \mathrm{O}-\mathrm{N}_{2}$ Atmospheres at 1273K, Corrosion Science. 1996; 38(1):19-31.

8. Bancroft GM. Mössbauer Spectroscopy. An Introduction for Inorganic Chemists and Geochemists. New York: Wiley. 1973. 252p.

9. Da Costa GM, De Grave E. de Bakker PMA, Vanderberghe RE. Influence of nonstoichiometry and the presence of maghemite on the Mössbauer spectrum of magnetite. Clay and Clay Minerals. 1995; 43(6):656-668. 
